\title{
Designing and building oncolytic viruses
}

\author{
Justin Maroun', Miguel Muñoz-Alía', Arun Ammayappan', Autumn Schulze', \\ Kah-Whye Peng ${ }^{1} \&$ Stephen Russell ${ }^{*, 1}$
}

Oncolytic viruses (OVs) are engineered and/or evolved to propagate selectively in cancerous tissues. They have a dual mechanism of action; direct killing of infected cancer cells crossprimes anticancer immunity to boost the killing of uninfected cancer cells. The goal of the field is to develop OVs that are easily manufactured, efficiently delivered to disseminated sites of cancer growth, undergo rapid intratumoral spread, selectively kill tumor cells, cause no collateral damage and pose no risk of transmission in the population. Here we discuss the many virus engineering strategies that are being pursued to optimize delivery, intratumoral spread and safety of OVs derived from different virus families. With continued progress, OVs have the potential to transform the paradigm of cancer care.

First draft submitted: 29 November 2016; Accepted for publication: 30 January 2017; Published online: 31 March 2017

\section{Viruses as anticancer drugs}

Oncolytic viruses (OVs), evolved and engineered for cancer specificity, are gaining momentum as a new drug class in the fight against cancer. Besides, causing the death of virus-infected cancer cells, the spreading intratumoral (IT) infection can also boost the anticancer immune response, leading to immune destruction of uninfected cancer cells. The paradigm of OVs has been reviewed extensively $[1-7]$.

The key desirable characteristics of any OV are specificity, potency and safety; specificity for the targeted cancer, potency to kill infected cells and cross-prime antitumor immunity, and safety to avoid adverse reactions and pathogenic reversion.

It is well established in several rodent cancer models that a single dose of an effective OV can completely cure disease $[8,9]$. This has been shown for DNA and RNA viruses in diverse tumor models. However, while the single shot cure is an exciting prospect for cancer therapy, to date clinical outcomes have typically fallen short of this, and repeat IT virus administration has proven to be a more reliable approach $[6,10]$. But there are a number of anecdotal case reports that give credence to the idea that a single shot OV cure may be achievable in clinical practice $[4,11]$ suggesting that OVs have the potential to transform the practice of oncology.

In light of recent clinical progress, interest in the approach is burgeoning. One critical milestone was the 2015 marketing approval granted in Europe and the USA for talimogene laherparepvec (T-Vec, Imlygic ${ }^{\mathrm{TM}}$ ), an engineered HSV encoding GM-CSF. This virus, administered intratumorally every 2 weeks for malignant melanoma, led to complete resolution in $47 \%$ of injected tumors and boosted systemic antitumor immunity leading to resolution of $9 \%$ of distant uninfected visceral tumors [12]. Subsequent clinical studies have shown that responses are more frequent and more durable when T-Vec (and other OVs such as coxsackievirus A21) is combined with immune checkpoint

'Department of Molecular Medicine, Mayo Clinic College of Medicine, Rochester, MN 55905, USA

*Author for correspondence: Tel.: +1 507284 8384; sjr@mayo.edu

\section{KEYWORDS}

- cancer therapy • oncolytic immunotherapy $\bullet$ oncolytic virotherapy $\bullet$ virus engineering $\bullet$ virus targeting 
inhibitor antibody therapy [13]. Another significant milestone was the demonstration that a systemically administered oncolytic measles virus can target and destroy disseminated cancer in a human subject [11].

Based on these clinical advances, development of OVs is rapidly accelerating. The purpose of this review is to discuss the virus engineering approaches and OV performance optimization strategies that are being pursued in the field, and to point out some of the challenges that remain. We believe this perspective will be particularly valuable to virologists entering the field. We apologize to the numerous investigators whose work has not been acknowledged; we are well aware of these omissions but due to space constraints our approach has been choosing illustrative examples that demonstrate the key principles. The review is divided into five main sections: (i) an introduction to viruses and virus engineering, (ii) delivery, (iii) spread, (iv) arming and (v) safety. All five topics are highly interdependent.

\section{Engineering viruses: a diversity of platforms}

In nature, viruses are continuously evolving and adapting to occupy almost every imaginable biological niche. Viruses infect bacterial, archaea, protist, fungal, plant and animal cells. Their genomes are composed of DNA or RNA, which may be single or double stranded, positive or negative sense, ranging in size from 2 to $300 \mathrm{~kb}$, in complexity from 1 to 300 genes and in capacity for foreign genetic material from a few hundred bases to several kilobases. The particles of viruses from different families also vary enormously in size and structure, ranging from 20 to $1000 \mathrm{~nm}$, from icosahedral to helical symmetry, with or without lipid envelope, integument or matrix and with variable susceptibility to physical disruption. Naturally occurring viruses also offer a vast diversity of virus life cycles, cell entry and replication mechanisms, cell and species tropisms, cycle times, burst sizes, innate immune evasion, apoptosis, antiviral state prevention and immune combat strategies, modes of transmission and pathogenic mechanisms. The diversity of viruses that have been investigated as oncolytic platforms and the different strategies used to improve their efficacy continue to be expanded (Table 1).

Aside from their differences, viruses share fundamental similarities including their dependence on the host cell to provide a suitable environment for genome amplification, gene expression and progeny virus production and their adaptation to a specific set of host cell conditions and factors such that propagation is precluded in cells that fail to provide the necessary environment. These characteristics allow viruses to be targeted to cancer cells as a self-replicating antineoplastic therapy.

As might be expected, proponents of a given OV are typically able to advance strong arguments to support their choice of platform, emphasizing unique features such as replication kinetics, genome plasticity, targetability, seroprevalence and stability that may lead to superior oncolysis. However, it is too early to determine which unique viral characteristics will be the critical drivers of clinical success for a given cancer type.

\section{- Designing \& engineering viruses for cancer therapy}

Reverse genetics systems are available for virtually all virus families, and the rules of engagement for new virus creation are well established. In general, the most effective strategy is to combine rational design with evolution, allowing each engineered virus to mutate and fully adapt to its intended target cells after it has been rescued. Biosafety oversight is in place at all academic centers responsibly engaging in virus engineering activities, and it is now a relatively straightforward matter to generate and test new virus configurations using what now amounts to the world's best lego set. Viral gene and noncoding sequences can be modified in a variety of ways to add or eliminate functions and nonviral genes or noncoding regulatory elements, whether synthetic or naturally occurring, can be added into viral genomes to confer additional desirable properties.

\section{- The goals of virus engineering}

The overarching engineering goal for the oncolytic virotherapy field is to generate viruses that can be efficiently delivered to disseminated tumors in the body where they will spread and selectively kill both infected and uninfected tumor cells, without causing collateral damage and posing no risk of transmission to the population.

\section{Delivery of OVs}

Viral infections are well understood but for OV applications must be viewed as drugs obeying 


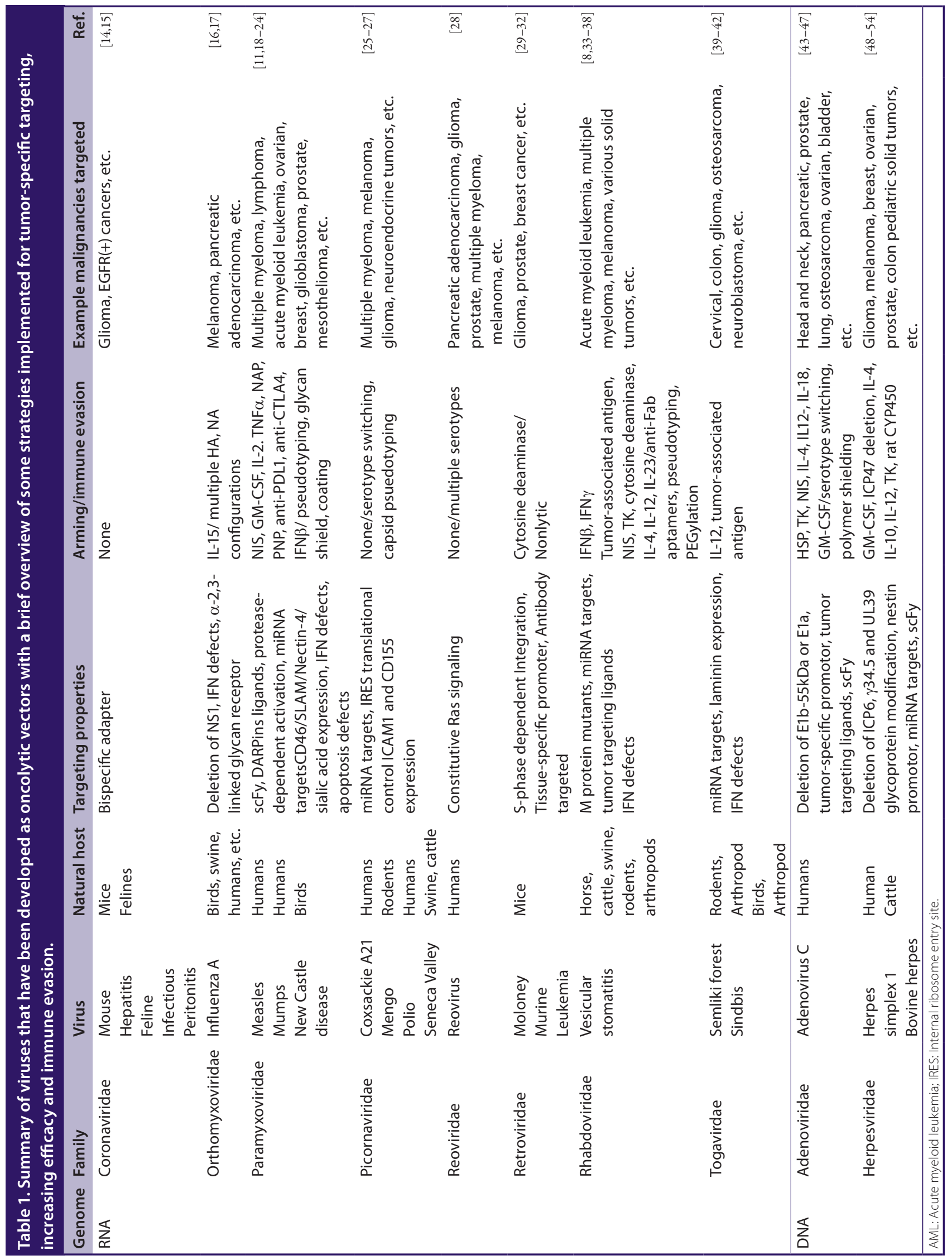




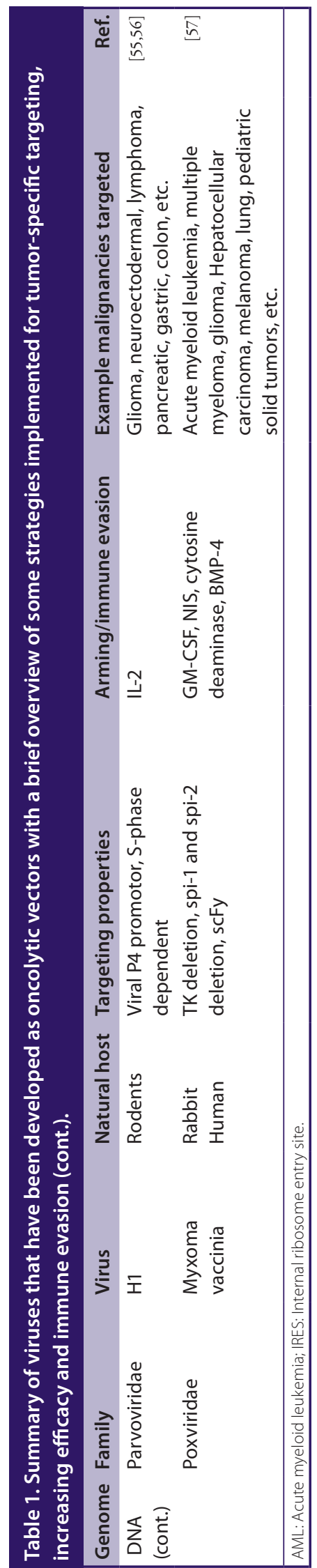

pharmacological principles. A drug is typically administered to a patient in an extremely controlled way to produce a reliable, consistent and predictable pharmacokinetic profile (absorption, biodistribution, metabolism and excretion) and bioavailability. Natural viral infections do not obey these rules since the inoculum is of variable size; host resistance varies from person to person; and the kinetics of the adaptive immune response differ greatly between individuals. Thus, the outcomes of natural infections with a given pathogenic virus range from asymptomatic seroconversion to full blown disease. The primary virus inoculum must contain sufficient virus particles to overcome initial host defenses at the site of entry. Some viruses enter through mucous membranes in the GI or respiratory tracts, while others enter via direct inoculation into the blood stream following a needle stick or arthropod blood meal [58]. OVs are delivered in the same way as traditional drugs, by introducing a highly concentrated virus inoculum into the body via oral, intravenous (IV), intranasal, transdermal, subcutaneous or intramuscular routes whereupon the dispersion of the inoculated virus, or its progeny, takes it to the targeted cancerous tissues. A major factor distinguishing OVs from traditional drugs is that they self-amplify and spread after delivery so their peak concentration may not be reached until sometime after the treatment is administered.

Biological amplification by viral replication is the most important difference between viral therapies and traditional drugs. The concentration of a drug diminishes over time at a very well described rate depending on the clearance and elimination from the body. Through the course of a viral infection the viral load is initially small and then increases and finally decreases rather than just following a specific rate law of elimination. Limited amounts of virus particles replicate at the site of inoculation [59]. Input or progeny viruses then can either drain with the lymphatic fluid to the nearest lymph node, go directly into circulation or spread locally before spreading systemically to eventually arrive at a specific target organ. Pathology is induced by high levels of viral replication in the target organ directly killing infected cells or recruiting the immune system to kill them, at the same time provoking a local inflammatory response.

OV therapy begins with the administration of the virus to the patient just as with any other drug. Several approaches can be taken, each with 
advantages and limitations, to deliver a sufficient quantity of virus to sites of tumor growth to seed a productive, tumor destructive infection. The ability to effectively and uniformly deliver the OVs to sites of tumor growth probably trumps all engineering strategies since even the most efficient, tumor-specific targeted virus will not achieve meaningful oncolysis if it does not reach the tumor cells. A single-shot cure can probably only be achieved if the viral infection is widely dispersed throughout all sites of tumor growth. A mathematical model developed by Bailey et al. to optimize oncolytic virotherapy indicated that maximizing delivery, so more tumor cells are infected, has a profound impact on the degree to which the virus must propagate from each infected cell for curative therapy [60]. The higher the number and the more random the dispersion of infectious centers established in a tumor after delivery of virus, the more effective the virus will be, although these parameters must be optimized for each virus and model [61].

IV and IT administrations of OVs are common delivery methods that introduce large amounts of virus into one compartment in a very short time. This rapid delivery of a massive virus inoculum does not parallel what typically occurs in a natural infection and potentially allows the IT spread of the OV infection to outpace host defenses. Successful delivery in the context of an $\mathrm{OV}$ infection requires that a critical viral concentration is achieved within the tumor to allow for sufficient oncolysis and systemic spread of the virus to all sites of disease in a safe and reproducible pattern.

\section{- IV delivery}

IV delivery of an OV seems advantageous in the setting of metastatic disease, allowing the virus to potentially access all sites of disease via the circulation soon after infusion. In a clinical setting, systemic delivery may be preferred since it is more broadly applicable than IT inoculation, regardless of tumor location and total tumor burden. Yet, attempts at systemic delivery have shown limited success; the administered virus is immediately diluted in the circulating blood volume ( $\sim 5$ l), so extremely high doses are needed to achieve meaningful circulating titers. A clinical trial using an oncolytic poxvirus, JX-594, demonstrated that virus could only be detected in tumors of patients that received at least $10^{9}$ p.f.u. per IV dose without any virus being detected in tumors of the lower dose cohorts of patients [62]. Because of this important dilution effect, doses required for IV therapy may have to be up to 1000 -fold higher than for IT administration, which results in significant manufacturing challenges as well as a unique set of toxicities [2]. Administration of high titers of virus intravenously can lead to hepatotoxicity, thrombocytopenia and lymphopenia $[33,63]$.

Following the path of an OV from the IV line to the tumor will quickly illustrate some of the challenges for IV delivery. First, the virus is rapidly diluted in the circulation, where its infectivity is neutralized by serum proteins including antibodies and complement, and a large proportion is sequestered by reticuloendothelial phagocytes in the spleen and liver. Any virus particles that reach the tumor vasculature without first being neutralized must then extravasate through fenestrations, and pores between the vascular endothelial cells of the tumor capillaries, and once in the interstitial space of the tumor, must negotiate the extracellular matrix (ECM) to reach and infect the resident cancer cell [64].

Tumor vasculature can both aid and limit viral access. Tumors typically have an unorganized growth pattern, producing vasculature that is tumultuous and insufficient resulting in heterogeneous perfusion throughout the parenchyma [65]. Decreased perfusion limits the formation of infectious centers evenly throughout a tumor. Manipulating physiological parameters such as blood pressure and systemic vascular resistance can preferentially increase tumor perfusion and promote better delivery of viral vectors [66]. Once in a tumor vessel, the virus must move from the intravascular compartment into the interstitium by crossing the vascular endothelium to continue its journey through the interstitial space until finally reaching a permissive tumor cell.

At least in theory, viruses can cross the endothelial lining of tumor neovessels by diffusion, active infection, or by trafficking inside of or on the surface of marrow-derived cells that are capable of diapedesis. Tumors generally have poor lymphatic drainage and can have leaky blood vessels with a wide range of pore sizes which helps to explain the phenomenon of enhanced permeability and retention of nanoparticles such as OVs in the tumor parenchyma [67]. In some tumors, the pores and fenestrations in tumor capillaries may be large enough to permit passive diffusion of viruses (depending on their size) but in many tumors 
the endothelium is sufficiently organized that this type of extravasation is simply not possible.

Clearly, the ability to infect the activated endothelial cells of tumor neovessels would be an attractive targeting property for OVs to enhance entry into the tumor parenchyma by releasing viral progeny on the ablumenal side of the blood vessel. Intravascular coagulation in the capillary could also be provoked by virusinfected endothelial cells reacting with clotting and inflammatory factors. Virus engineering strategies have been pursued to achieve this goal, for example, by displaying polypeptide ligands echistatin and urokinase plasminogen activator on the surface of measles virus to target integrin $\alpha \mathrm{V} \beta 3$ and UPaR endothelial cell surface receptors, respectively $[68,69]$. Also, at least one OV (vesicular stomatitis virus VSV) has been shown naturally capable of infecting neovessel endothelium in implanted mouse tumors, but the study did highlight the potential toxicity of the approach, namely intravascular coagulation requiring heparin therapy for its prevention [70].

Another approach to help OVs' extravasate is by temporally creating pores throughout the tumor microvasculature to enhance transport of the virus into tumor interstitium. This can be done through application of focused ultrasound in the presence of a contrast agent or a polymer. The microbubbles or polymers are injected intravenously and can freely circulate without harming tissues, but when they are exposed to ultrasound waves they can oscillate and induce pore formation or cavitation in the surrounding tissue. The ultrasound can be focused on a tumor just after the infusion of the virus to increase viral extravasation. This has been shown to enhance vaccinia virus delivery to tumor xenografts and can increase viral transgene expression by more than a 1000 -fold in the tumor [71,72] Many strategies are being developed to enhance OV IV delivery.

\section{- IT delivery}

IT administration directly delivers a high concentration of the OV into the parenchyma of the injected tumor but may not result in spread of the virus to distant sites of metastasis. T-Vec is administered by IT injection to accessible skin tumors of patients with metastatic malignant melanoma. The injection is repeated every 2 weeks until lesions have resolved or failed to respond $[12,73]$. Interestingly, viremia was not documented in patients, suggesting that the regression of noninjected lesions was likely immune-mediated and not due to direct oncolysis [74].

Immediately following IT delivery, small levels of virus can be detected in the blood from leakage through injured tumor vasculature [75], but that small amount of virus is quickly cleared from the system. Also, virus that has been injected into a tumor is frequently extruded immediately from the injection track once the syringe is removed, especially in smaller higher pressure tumors. However, systemic viral spread can occur following IT administration if the initially exposed tumor cells are capable of amplifying the input virus and releasing progeny into the bloodstream. Such secondary viremia may not peak until several days after IT virus delivery and, with currently used OVs, is often not detected. Secondary viremia, when it occurs, more closely mimics the natural propagation of a viral infection from the site of inoculation to more distant target organs.

Mouse models with implanted flank tumors provide a convenient model for IT injection as the tumor is superficial, but in human patients with spontaneous malignancies tumors often develop internally in visceral organs. Melanoma, head and neck cancer, and lower gastrointestinal malignancies may be better suited for IT injections due to anatomical position, although with advanced interventional radiology using computed tomography or MRI image guidance to place the needle many more tumors may be accessible for IT virotherapy. One additional advantage of IT injection over the IV route is that the threshold concentration of input virus required to initiate a spreading infection in the tumor tissue can be more easily achieved.

\section{- Other routes of delivery}

Intraperitoneal virus administration is often pursued in virotherapy studies aiming to impact ovarian cancer and other disseminated intraperitoneal malignancies, while intrapleural administration is pursued for mesothelioma therapy. Both of these approaches are similar to IT administration in that the virus comes into direct contact with tumor cells in the injected cavity, although there is a greater risk that input virus will be immediately neutralized by antibodies and other proteins in ascites or pleural fluid. Intravesical instillation of virus is the favored route of administration for treatment of early-stage bladder cancer, requiring only that 
the input virus be stable in urine. Also, immediately after brain cancer surgery, in an attempt to control residual disease, virus is often instilled directly into the resection cavity.

\section{- Limiting viral neutralization \& clearance}

Perhaps the most significant barrier to widespread OV delivery is rapid neutralization and clearance of circulating virus particles. Antibodies and complement proteins can coat the virus blocking its ability to interact with its cellular receptor and accelerate $F_{c}$ receptor-mediated clearance by splenic macrophages and hepatic Kupffer cells.

Antibody neutralization has been shown to reduce the efficacy of systemically administered OVs such as measles, VSV and vaccinia in preclinical models [76-78]. When previous exposure has occurred, preformed antibody reduces the effectiveness of the initial treatment. However, the situation is typically far more problematic for second and subsequent doses, even for low seroprevalence viruses, because the first dose induces a powerful primary antiviral antibody response or boosts the pre-existing response $[79,80]$. These troublesome responses can be constrained by coadministering immunosuppressive drugs such as cyclophosphamide. Cyclophosphamide administered concurrently with an $\mathrm{OV}$ has been shown to suppress or delay the development of humoral and cytotoxic antiviral T-cell responses [81].

For high seroprevalence viruses, one approach to circumvent viral neutralization by preformed antibodies is to engineer or switch the viral coat proteins. Some OVs (e.g., adenovirus) offer a menu of different serotypes, providing a basis for serotype switching between successive doses of the therapy to avoid antibody neutralization, although this does greatly complicate the product development pathway since each serotype is considered to be a distinct pharmaceutical product [82]. For monotypic viruses such as measles, serotype switching is not an option, but antimeasles antibodies can be circumvented by substituting the surface glycoproteins of measles with those of a related but noncross-reactive morbillivirus such as canine distemper virus [83]. Alternatively, the immunodominant epitopes of the measles surface glycoproteins can be modified by mutating key surface residues to eliminate them, or by introducing glycosylation signals so they are shielded by N-linked glycans [84]. It is worth noting that all of these virus engineering strategies have the potential to alter viral receptor usage and hence tumor cell tropism which may limit their utility [83,85].

Mengovirus, VSV and Newcastle disease virus are examples of animal pathogens being developed as oncolytic agents. Their appeal as oncolytic platforms is due to the coupling of their ability to selectively propagate in human tumors with their low seroprevalence in the human population [77]. Unlike viruses such as measles which have almost exclusively human cell tropism, these zoonotic viruses are capable of infecting both rodent and human tumor cells allowing preclinical testing in more informative immunocompetent mouse cancer models.

Another strategy for avoiding neutralization is to block the reticuloendothelial system with polyinosinic acid or with clodronate-loaded liposomes which poison or deplete splenic macrophages and Kupffer cells. This approach has been shown to slow the clearance of circulating virus particles that have been coated with antibodies or complement [86-88].

Virus-infected cell carriers can also be used to transport viruses via the bloodstream to sites of tumor growth. In part, this is possible because there is an 'eclipse period' after the cell carriers have been infected during which they do not display viral proteins on their surface and are therefore not bound by virus neutralizing antibody, but are still able to extravasate from tumor neovessels and release infectious progeny into the tumor parenchyma. Several cell carrier/OV combinations have been used including mesenchymal stem cells, dendritic cells, $\mathrm{T}$ cells and endothelial progenitor cells [89-92]. Some carrier cells are believed to home more efficiently to tumors responding to chemotactic signals arising from hypoxia or IT inflammation.

\section{OV spread}

Replication and amplification in the tumor is the major feature that sets OVs apart from other anticancer drugs. No traditional chemotherapy, immunotherapy or small molecule inhibitor can target tumor cells and then amplify at the site of action and spread to other sites of tumor growth. Specificity as well as speed and extent of IT virus replication are the key determinants of therapeutic index (efficacy/toxicity ratio) for an $\mathrm{OV}$ therapeutic, and each of these parameters can be modified by virus engineering. Additionally, the kinetics of spread can be impacted by combining the virus with immunomodulatory drugs. 


\section{- Targeting virus tropism}

The idea of a virus with selective tropism for cancerous tissue has obvious appeal. Even for naturally occurring viruses that have not been tropism modified, a tumor offers a favorable environment to support a productive infection, and this is borne out by case reports of temporary remission or regression of different cancers concurrent with viral infections $[4,93]$. There are several reasons why tumors are generally more susceptible than normal tissues to virus attack; poorly developed lymphatics, high nonsuppressible metabolic activity, resistance to apoptosis, poor responsiveness to interferon and intrinsic suppression of immune effector cells. But as we move in the direction of intentionally using virus infections to mediate tumor destruction, it is apparent that a targeted virus with exquisite tumor specificity will be superior to its nontargeted counterpart, allowing for the administration of higher tumor destructive doses without toxicity to normal tissues.

Virus tropism is determined by many factors, most of which, if understood sufficiently, can be manipulated to enhance tumor specificity. The receptor tropisms of naturally occurring viruses are rarely of interest for tumor targeting, but this is not true for tissue-culture-adapted vaccine lineage viruses, some of which have evolved in the laboratory to use receptors more abundantly expressed on cancer cells. Examples include the CD46 receptor tropism of vaccine lineage measles virus and the heparan sulfate tropism of laboratory-adapted Sindbis virus [94,95]. Where greater specificity is desired, it may be possible to engineer new receptor tropisms by modifying the structure of a viral attachment protein, for example, by displaying polypeptide ligands at the extreme C-terminus of the measles $\mathrm{H}$ glycoprotein $[96,97]$. However, for many viruses, displaying a polypeptide ligand on the surface does no more than redirect attachment and does not confer a new receptor tropism [98-100]. This remains an area of active investigation.

In addition to their dependence on specific entry receptors, the surface glycoproteins of many enveloped viruses (and sometimes other critical viral proteins) must be proteolytically activated before they are competent to mediate virus entry [101]. By engineering the protease target sequences in these viral glycoproteins it is possible to generate viruses whose propagation is now dependent on exposure to a specific protease with high IT abundance, such as urokinase, matrix metalloproteinase 1 or cathepsin D [102-104].

Beyond the step of cell entry, viruses are exquisite sensors of intracellular processes and can therefore be adapted or engineered in several ways for intracellular targeting of cancer cells. This is best understood by considering some fundamental aspects of the interplay between a virus and an infected cell. The incoming virus aims to usurp the cellular synthetic machinery for generation of progeny viruses. The cell resists this takeover bid by rapidly detecting virus invasion, then triggering a signaling cascade that leads to establishment of an antiviral state and release of interferon which induces an antiviral state in adjacent cells $[105,106]$. The antiviral state is very complex but suppression of protein translation is a key component. Apoptosis is also triggered by the virus detection machinery so that the infected cell dies before it is able to manufacture virus progeny [107].

For a virus to be 'successful' it must combat these host cell responses, avoiding detection, as long as possible, for suppressing the establishment of an antiviral state and preventing apoptosis. Virtually all naturally occurring viruses therefore encode proteins that inhibit apoptosis and the antiviral state [108]. Removing these accessory functions from the viral genome leads to virus attenuation in normal tissues, but to a much lesser degree in cancerous tissues. This is because cancer cells are intrinsically resistant to apoptosis and to the establishment of an antiviral state, making them highly susceptible to attenuated viruses that are no longer able to control those processes. This has provided a mechanistic basis for physiologic targeting of several viruses; VSV by mutating the matrix gene whose encoded protein blocks the interferon response [109]; HSV by mutating both copies of the $\gamma-34.5$ gene which interferes with interferonmediated shutoff of host protein synthesis and enhances neurovirulence $[110,111]$; adenovirus by mutating the $\mathrm{E} 1 \mathrm{~B}$ protein, one of whose actions is to inhibit the apoptotic activity of p53 [112].

Viruses can be further engineered to exclusively replicate in tumor cells by combining a virus' needs with physiologic peculiarities intrinsic in tumorigenesis. For example, a virally encoded thymidine kinase (TK) is required for $\mathrm{HSV}$ and vaccinia virus infection to increase the supply of deoxynucleotide triphosphates required for synthesis of progeny virus genomes [113,114]. Elimination of the TK 
gene from the viral genome restricts viral replication to cancer cells where there is an upregulation of human TK [115,116]. Another example of a virus that exploits the high replication rate of tumor cells is Toca-511, a replication competent $\mathrm{C}$-type retrovirus encoding the drug activating enzyme cytosine deaminase (CD) [117]. Since the integration of C-type retroviruses is $\mathrm{S}$-phase dependent [118], this virus is selectively amplified in rapidly proliferating tumor tissue.

Engineering tumor specificity can also be achieved by detargeting viruses to ablate unwanted tropisms that can cause off target pathology in normal tissues. MircroRNA targeting is the best example of this approach. For example, miRNA targeting was used to control the tropism of an oncolytic coxsackievirus A21 virus which caused rapid tumor regression followed by fatal myositis in murine models of myeloma and melanoma [119]. Insertion of muscle-specific miRNA targets into the viral genome eliminated muscle toxicity but left the antitumor potency of the virus intact. This was shown to be due to miRNA-mediated recognition and rapid destruction of the viral genome in muscle cells. miRNA targeting has since been applied to many OVs from diverse virus families and provides a convenient and economical strategy (using sequence insertions of only 100 bases) to control unwanted virus tropisms [25].

\section{- Viral amplification \& spread}

After an appropriately targeted virus has infected a tumor cell, it is the extent of its subsequent propagation that becomes the key driver of potency. Data-driven mathematical models of systemic oncolytic virotherapy indicate that tumor eradication is dependent on two major parameters: the initial density and distribution of infectious foci in the tumor; and the ultimate size of the infectious centers arising from each individual infected cell (i.e., virus spread) [120]. Viral spread may occur by various mechanisms. Local spread may occur by intercellular fusion, by direct transfer of virus from infected to adjacent cells, or by release and local migration of progeny virions through the interstitial space. Systemic spread as free virus particles or as virusinfected migratory cells occurs via lymphatic channels or via the bloodstream.

Direct cell-to-cell transfer of viruses has the advantage of stealth as the virus cannot be neutralized by antiviral antibodies in the interstitial fluid [121]. Nonfusogenic viruses can be armed with fusogenic membrane glycoproteins (FMGs) to enable stealthy spread through intercellular fusion leading to the formation of large, nonviable multinucleated syncytia which may also serve as excellent antigen presenting cells for amplification of the antitumor immune response [122]. By way of example, VSV encoding measles fusogenic glycoproteins and HSVs encoding the fusogenic gibbon ape leukemia virus glycoproteins have shown superior efficacy when compared with their corresponding parental viruses [123,124].

In the case of free virus particles, which are susceptible to antibody neutralization, the stroma of the tumor also has the potential to limit IT diffusion and block systemic release. Fibroblasts, endothelial cells, immune cells and the ECM make up the tumor stroma, and the exact composition varies widely depending on tumor type [125]. The ECM is a collagenous matrix of protein fibrils, adhesive proteins and proteoglycans that create a web with pore sizes similar or slightly smaller than virions [126]. Destruction of ECM components can facilitate viral spread throughout the tumor and can be achieved using conventional chemoradiotherapy or by delivering matrix-degrading enzymes such as collagenase and hyaluronidase [127]. An alternative approach is to encode a matrix-degrading enzyme or inducer of matrixdegrading enzymes in the viral genome. For example, hyaluronidase and relaxin encoding oncolytic adenoviruses have each been shown to spread more efficiently in experimental tumors [128-130].

Another factor that significantly impacts the kinetics of virus spread is the burst size, or the number of progeny viruses released by a productively infected cell, which varies widely between viral families. Picornaviruses, VSV and vaccinia virus can release up to 10,000 progeny from a single infected cell after a delay of only $6-18 \mathrm{~h}[131-133]$. In addition to innate antiviral immunity, adaptive cell-mediated immune responses are typically required for the complete elimination of a viral infection and act by eliminating infected cells before progeny can be released. Oncolytic virotherapy can therefore be viewed as a race between the spreading virus and the responding immune system. For this reason, faster moving viral infections are often considered capable of inflicting greater damage to an infected tumor before they can be contained by the immune system [134]. However, in defense of the viruses with smaller burst sizes, or which release progeny by budding, they tend to be less 
rapidly controlled both by the innate and adaptive host immune responses [135]. Therefore, as with the classic race between the hare and the tortoise, it is very difficult to predict whether a fast or slow replicating virus will show superior efficacy in a given preclinical cancer model.

\section{Arming OVs: extending the range}

No matter how extensively an OV infection spreads through a tumor, a sizable percentage of the cancer cells will escape infection [61]. Killing of these uninfected (bystander) cancer cells is therefore critical if oncolytic virotherapy is to become a curative, as opposed to just a tumor debulking strategy. Bystander killing can be achieved, both locally at the site of a spreading infection and systemically at uninfected tumor sites, by genetically arming the virus using one of several possible approaches. For example, an OV can be engineered to encode a secreted protein that selectively mediates the destruction of neighboring and/or distant cancer cells. Alternatively, it can be armed with a 'suicide gene' or prodrug convertase whose encoded protein converts a harmless prodrug to a diffusible anticancer drug. In a third approach, the OV can be armed with a 'radioconcentrator gene' so that infected tumor cells are able to concentrate a $\beta$-emitting radioisotope whose emitted electrons damage adjacent uninfected tumor cells. Fourth, it can be engineered to fuse infected tumor cells with uninfected neighboring cells. And last, but by no means least, it can be engineered to express one or more genes capable of amplifying immune-mediated killing of uninfected tumor cells. Each of these approaches is discussed below using specific examples to illustrate the concepts.

\section{- Secreted toxins}

As a general rule, if a virus is to be armed with a gene encoding a secreted toxin, that toxin should be targeted so that it can kill only cancer cells. In the absence of such targeting, there would be little prospect of avoiding off-target toxicities. Immunotoxins are bifunctional proteins in which plant or bacterial toxins (typically ribosomal inhibitors) are fused to a single chain antibody or other polypeptide domain to target endocytosis in cancer cells [136]. In theory, such molecules that have been extensively investigated and advanced to human clinical trials particularly for the treatment of B-cell and T-cell malignancies [137], could be expressed from an engineered OV genome.

\section{- Prodrug convertases}

Unlike secreted toxins, prodrug convertases do not pose a risk of increasing OV virulence because their toxic potential is manifest only in the presence of an exogenously added prodrug. For this reason, the approach has been extensively studied. Perhaps the most well-known convertase-prodrug combination is HSV TK, used with ganciclovir. TK converts ganciclovir to ganciclovir monophosphate which is further processed intracellularly to ganciclovir triphosphate, a DNA synthesis chain terminator that kills dividing cells as they enter $S$ phase [138]. A major weakness of the TK-ganciclovir system, aside from its inability to kill nondividing tumor cells, is that it has very limited bystander killing potential. This is because ganciclovir monophosphate is not released from the cell in which it is generated, so does not impact uninfected tumor cells unless they are connected to the infected cell via gap junctions through which it can pass [139]. Encoding connexin, a gap junction protein, in the OV genome can enhance the bystander killing effect of TK, but attention is shifting to other convertases, most notably CD.

$\mathrm{CD}$ converts 5-flurocytosine (5-FC), an inert small molecule that is administered intravenously, to 5-flurouracil (5-FU), an antimetabolite that irreversibly inhibits thymidylate synthase and is an approved chemotherapeutic agent for a variety of cancers (anal, breast, colorectal, esophageal, stomach, pancreatic and skin) [29]. The argument supporting the CD/5-FC system is that local production of $5-\mathrm{FU}$ in the OV-infected tumor will create a 5-FU concentration gradient that will expose tumor cells to a higher concentration of the drug compared with distant tissues, thereby ameliorating toxicity and enhancing the therapeutic index of the drug. However, 5-FU is freely diffusible so local production of the drug in a $\mathrm{CD}$-positive tumor exposed to high concentrations of 5-FC can lead to systemic toxicity [140]. The dose of 5-FC must therefore be adjusted accordingly. $\mathrm{CD}$ has been incorporated into several OVs including adenoviruses, paramyxoviruses and poxviruses, but the one that has advanced ahead of all others in clinical testing is a C-type retrovirus, Toca-511, which is currently being evaluated in a Phase III clinical trial for the treatment of patients with malignant glioma [141-143]. Besides the TK and $\mathrm{CD}$ prodrug convertase systems, there are reports of OVs engineered to express the cyclophosphamide-activating protein CYP2B1, 
the CPT11-activating secreted human intestinal carboxylesterase (shiCE) and the fludarabine phosphate activating purine nucleotide phosphorylase [144,145].

\section{- Sodium iodide symporter (radioconcentrator)}

Iodide is a critical component of thyroxine and is concentrated in thyroid follicular cells by the thyroidal sodium iodine symporter (NIS), a cell surface glycoprotein with 13 transmembrane domains [146]. Radioiodine is therefore used routinely in the clinic for thyroid imaging and for ablation of overactive thyroid tissue, including metastatic thyroid cancer. This is facilitated by the ready availability of several iodine radioisotopes, most notably ${ }^{123} \mathrm{I}^{-}$for $\gamma$ camera and single-photon emission computed tomography imaging, ${ }^{124-}$ for $\mathrm{PET}$ imaging and ${ }^{131} \mathrm{I}^{-}$, a $\beta$-emitting isotope, for thyroid ablation. Besides radioiodine, NIS can concentrate several related anions, of equal or greater value for single-pho-

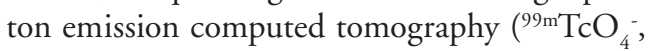
pertechnetate), PET $\left(\mathrm{B}^{18} \mathrm{~F}_{4}^{-}\right.$, tetrafluoroborate) and tissue ablation $\left({ }^{211} \mathrm{At}\right.$, astatide, ${ }^{188} \mathrm{ReO}_{4}^{-}$, perrhenate) [147]. The $\beta$ emissions of ${ }^{131} \mathrm{I}^{-}$have an average path length of approximately $1.8 \mathrm{~mm}$ in tissue and can therefore inflict significant damage on cells adjacent to an ${ }^{131} \mathrm{I}^{-}$-loaded NIS expressing cell. For ${ }^{188} \mathrm{ReO}_{4}-$ the $\beta$ emission path length is longer such that NIS negative tumor cells are even more likely to be damaged in the $\beta$ particle crossfire when this radioisotope is used. Unsurprisingly, therefore, the NIS gene has been engineered into several OVs whose IT spread has been elegantly mapped and monitored in tumor-bearing mice by serial radiotracer imaging, and whose potency has been substantially boosted by appropriately timed administration of ${ }^{131} \mathrm{I}^{-}[148]$. At least two NIS-expressing OVs, a prostate-targeted oncolytic adenovirus and a CD46-targeted measles virus, have been advanced to human clinical trials with positive imaging data reported [11,149].

\section{- Fusogenic membrane glycoproteins}

Fusion of the lipid envelope of an incoming virus with the limiting membrane of its target cell is a necessary step in the life cycle of an enveloped virus, to deliver the encapsidated viral genome into the target cell cytoplasm. This virus-to-cell fusion reaction is mediated by FMGs embedded in the envelope of the virus, and may occur at the cell surface at neutral $\mathrm{pH}$, or in the endo- somal compartment at acidic $\mathrm{pH}$ [150]. Neutral $\mathrm{pH}$ fusion is triggered by receptor attachment. Cells expressing certain virally encoded, neutral $\mathrm{pH}$-active FMGs on their surface may fuse with neighboring receptor positive cells (cell-to-cell fusion), giving rise to multinucleated syncytia, the hallmark cytopathic signature of a fusogenic virus (e.g., measles) [151]. But more often the FMG is activated only after its incorporation into a budding virus particle, so cannot cause cell-tocell fusion, and must be modified, for example, by cytoplasmic tail truncation, to render it constitutively fusogenic. Either way, FMG-driven fusion of OV-infected cells with uninfected neighboring cells leads to increased bystander killing because multinucleated syncytia are nonviable as well as being highly immunogenic [152] . Based on these observations, nonfusogenic OVs have been armed with FMGs thereby conferring superior oncolytic potency $[123,153]$. In one example, an oncolytic herpes virus was rendered highly fusogenic when engineered to encode a cytoplasmically truncated gibbon ape leukemia virus envelope glycoprotein [154-156] while in another study, an oncolytic VSV was rendered highly fusogenic by replacing its surface glycoprotein $(G)$ with the hemagglutinin and fusion glycoproteins of measles virus.

\section{- Arming OVs to amplify antitumor immunity}

Tumor cells are intrinsically immunogenic because of their mutational burden. 'Driver' mutations disrupt their ability to respond to normal growth regulatory signals whereas 'passenger' mutations occur at random throughout the genome and are unique to a given tumor. Some of these mutations change the coding sequence of an expressed protein, resulting in the generation of nonself-peptides that can be presented at the cell surface as neoantigenic MHC-peptide complexes or neoepitopes [157]. In order to avoid immune detection and destruction, cancers must therefore evade the immune system, which they do very effectively. Thus, tumors lack lymphatic channels and sustain high interstitial pressures, impeding leucocyte extravasation. They release immunosuppressive substances such as prostaglandin E2 and TGF $\beta$ and reprogram macrophages from M1 to M2 phenotypes, destroying their ability to process and present tumor antigens. They may even lose the ability to present MHC-peptide complexes on the tumor cell surface [158]. Many tumor 
cells also overexpress PD-L1 and B7.1 receptors on their surface as a last line of defense against attacking $\mathrm{T}$ lymphocytes. These checkpoint receptors interact with $\mathrm{PD}-1$ or CTLA4 on the surface of approaching $\mathrm{T}$ cells, leading to T-cell anergy. Checkpoint inhibitor antibodies, which are currently transforming the field of immunooncology, block these PD-1/PD-L1 and/or CTLA4/B7 interactions thereby 'unveiling' the cancer and rendering it susceptible to T-cellmediated killing [159]. Because of their ability to amplify immune-mediated killing of uninfected tumor cells, OVs may be ideal partners for checkpoint inhibitor antibody therapy and can be engineered in various ways to maximize their immune enhancing properties $[13,160]$.

Immediately following $\mathrm{OV}$ infection, tumor cells release type I interferons, driving innate and inflammatory immune responses [161]. Subsequently, they undergo necrosis releasing tumor antigens into the interstitial space where they are phagocytosed by inflammatory effector cells and transported to regional lymph nodes for cross-presentation to helper and effector $\mathrm{T}$ cells which proliferate, re-enter the bloodstream, traffic back to the tumor, extravasate from tumor neovessels, engage the neoantigenic MHC-peptide complexes on uninfected tumor cells and kill them [162-164].

Each step of the above process can be impacted by virus engineering. Not only can the kinetics and mode of cell killing be manipulated (see the previous section on virus spread), but also the OVs can be armed with a wide variety of immunoregulatory genes whose products will be secreted into the interstitial fluid space. Thus, OVs have been engineered to express the following: high levels of type I interferons to better drive the early innate/inflammatory response; GM-CSF to stimulate the phagocytic activity and lymph node trafficking of professional antigen presenting cells; chemokines to enhance the IT recruitment of immune and inflammatory effector cells, especially cytotoxic T cells; cytokines to drive the activation and proliferation of tumor-resident cytotoxic T cells; bispecific T-cell engagers to enable tumor cell killing by $\mathrm{T}$ cells not recognizing tumor antigens; checkpoint inhibitor antibodies to block the protective PD-L1/B7.1 shield that protects tumor cells from T-cell attack; cytokines to increase MHC-peptide neoantigen expression on uninfected tumor cells; or cloned tumor antigens to further amplify tumor-specific immunity [165]
While each of these approaches has proven beneficial in selected preclinical animal models where immune destruction of the tumor is the dominant $\mathrm{OV}$ effect, they are equally likely to decrease potency by speeding virus elimination in situations where the spread of the virus is dominant.

\section{Safety}

Engineering viruses for increased stealth, greater specificity, faster spread and enhanced potency is not without risk. As OVs gain new properties, checks and balances must be applied to assure that they do not readily evolve into pathogens, let alone transmissible pathogens that could pose a risk not only to immediate contacts of the treated patient, but also to the greater population.

So far OVs have an exceptional safety record in the clinic with few serious adverse events and minimal mortality reported from human trials $[166,167]$. However, since efficacy has also been limited, it remains possible that toxicity profiles may appear less favorable as doses are increased and as newer OVs or virus-drug combinations are advanced to clinical testing. Currently, there are over 40 active clinical trials ongoing using OVs alone or in combination with other therapies [168]. As the number of patients participating in trials grows so will the insight into rare adverse effects. The most common adverse effects reported in recent $\mathrm{OV}$ trials are fever and flu-like symptoms [169]. However, the potential for severe adverse reactions was much more clearly demonstrated in the earliest virotherapy trials undertaken in the 1950s and 1960 s when deaths and severe adverse reactions were not infrequently recorded due to presumed OV replication in normal tissues, notably the brain, especially in immunocompromised cancer patients $[4,170,171]$.

\section{- Limiting pathogenicity}

Viral cytotoxicity is the basis of tumor cell death necessary for oncolytic activity. Off-target infection and killing of normal cells by poorly targeted OVs or by OVs that have evolved new tropisms in a treated patient can cause unwanted normal tissue pathology. OVs are therefore delicately balanced between retaining enough virulence to substantially decrease tumor burden versus being sufficiently targeted (or attenuated) to not cause a new disease in the patient. Cancer-specific targeting is the most critical safety 
feature, but viruses evolve and viral populations are dynamic [172]. Evolution is a constant accompaniment of a spreading virus infection, whether or not the virus is oncolytic; in vivo progeny of the therapeutic OV differs on average by a single -point mutation per genome from the input virus [173]. Hence, as the input virus is amplified, it generates a swarm of quasispecies viruses, each one a slightly imperfect replica of the input virus. This swarm of progeny viruses is subjected to selective pressure as it encounters new biological niches in the treated cancer patient. Thus, if it so happens that a member of the swarm is capable of infecting a normal host tissue, the virus may have gained a new foothold from which to further evolve. Gaining new cell tropisms or losing restriction factors is therefore a significant theoretical concern in oncolytic infections, but has not yet been documented in human trials, nor in preclinical models. However, given the importance of this particular scenario, a great deal of attention is paid to the problem not just by investigators, but also by regulatory agencies.

Understanding the selective pressures that operate within the tumor and the host, as well as the role of viral quasispecies in treatment outcomes is an active area of research. RNA and DNA viruses exist as a population of quasispecies or collections of related viral genomes undergoing variation and selective pressure [174]. Generation of quasispecies occurs when viral genomes are copied during the replication cycle. Viral polymerases typically have an error rate that introduces an average of one or more base mutations per progeny genome [175]. In general, the larger the virus genome, the lower the polymerase error rate. Picornaviruses are among the smallest viruses being developed for oncolytic therapy with positive sense RNA genomes ranging from 7 to $9 \mathrm{~kb}$ in length, and their RNA polymerases have a correspondingly high intrinsic error rate. Production of a virus for clinical application is a highly regulated process and involves multiple rounds of replication to achieve enough virus for patients. The viral product is therefore already a swarm of quasispecies at the time it is administered to the patient and mutates further as it undergoes additional rounds of replication in vivo. Studies of the mutation rates of viral polymerases, the generation of quasispecies, the evolution of viral populations and the evolution between dominant subspecies within a virus population are therefore of great interest and relevance to the OV field.
Although it will be interesting to determine whether OVs encoding modified polymerases with higher fidelity will exhibit an improved safety profile [176], it should be noted that OV reversion to a more pathogenic state has not yet been observed clinically. This is also true of many time-honored viral vaccines. For example, in 50 years of widespread measles vaccination using attenuated Edmonston lineage substrains, there has never been a documented reversion back to a wild-type phenotype, even after IV doses as high as $10^{11}$ TCID $_{50}$ were administered to immunosuppressed, measles antibody negative myeloma patients in an oncolytic virotherapy study [177].

Polymerase infidelity is not the sole driver of virus genome diversification and evolution. For many viruses, recombination between homologous viral genomes can occur when two related viruses infect the same cell [178]. This type of recombination is not a feature of negative strand RNA virus evolution because the nascent progeny viral genomes are cotranscriptionally incorporated into a helical ribonucleocapsid structure which prevents recombination. However, for positive sense RNA picornaviruses, and DNA viruses such as adenovirus, HSV and vaccinia, it is important to consider the possibility that the input virus may encounter and recombine with a homologous 'wild-type' virus in a treated patient. While such recombination has never been documented in OV trials, there are well described examples in the field of vaccinology, such as the re-emergence of pathogenic polioviruses through the recombination of vaccine genomes and naturally circulating picornavirus genomes [179]. In view of these risks, it is generally considered inadvisable to arm viruses with therapeutic transgenes that have theoretical potential to increase pathogenicity if transferred to a related naturally circulating virus. Genes encoding immunosuppressive, antiapoptotic or directly cytotoxic proteins are on this list.

Certain viruses with segmented genomes, most notably the orthomyxoviruses (e.g., influenza), are capable of rapid evolution by genome fragment reassortment in multiple infected cells. Reassortment of genome fragments in virus-infected birds and pigs is considered to be a key driver of the antigenic shifts that occur during evolution of new pathogenic influenza virus strains [180]. This important safety concern may explain why oncolytic influenza viruses have not yet been advanced to human clinical trials [181]. 
Because of the toxicity risks associated with the proliferative and evolutionary capacity of OVs, there is considerable interest in contingency plans to terminate the spread and/or transmission of an OV infection. Reliable antiviral medications are available for TK-expressing herpes viruses, but this is not the case for the majority of viruses being developed as OV platforms [182,183]. Attention has therefore been directed to the development of safety switches that can be engineered into the OV genome and triggered on demand to terminate in vivo replication.

Two so-called suicide genes, TK and inducible caspase 9, are of interest in this regard. Both of these genes have been used as a safety switches to eliminate genetically modified $\mathrm{T}$ cells that were causing graft versus host disease in human clinical trials [184-186]. Viruses engineered to encode TK have also been controlled with ganciclovir therapy [187], but this cannot be considered a reliable safety switch because of the ever-present risk of the emergence of viral quasispecies with TK inactivating mutations. The development of a universal and highly reliable safety switch remains one of the significant research challenges facing the field of oncolytic virotherapy.

Limiting the pathogenic potential of OVs can also be accomplished by enhancing the host innate immune response. VSV has been engineered to express IFN- $\beta$, which induces an antiviral state and reduces proliferation of cells. Cells capable of responding to interferon signaling will limit viral replication in response to the virally produced interferon, further restricting viral replication to tumors with defective innate responses [188]. The expression of IFN- $\beta$ from infected tumor cells can also prevent off-target infection of nearby tissue through paracrine signaling. Another way to achieve a similar effect is mutating the VSV matrix protein, which is responsible for limiting cellular production of type I interferons [189]. This, and similar approaches, to inactivate viral genes that combat innate immunity has been extensively utilized in the OV field, across a broad range of viral families. Sensitization of OVs to innate immune responses can limit off-target infections and enhance tumor-specific tropism while increasing the therapeutic index.

\section{- Limiting transmissibility}

For obvious reasons OV transmission from a treated patient to a caregiver, family member, coworker, pet or other species is highly undesir- able. Infectious virus particles may be present in the blood of a treated patient, and may be shed into the environment in urine, feces, saliva and other bodily secretions. Contact with the body fluids of an OV-treated patient therefore may have the potential to spread an infection to new hosts [190].

Because the risks of OV transmission are typically unknown when first-in-human Phase I trials are initiated, it is usual to implement standard infection containment measures throughout these studies and to carefully monitor body fluids for the appearance and disappearance of viral genomes and infectious virus progeny [191] For certain viruses, containment may be considered unnecessary, particularly when there is already widespread population immunity to the $\mathrm{OV}$ in question (e.g., measles) or when there has been extensive human experience of exposure to a related virus in the form of a live viral vaccine (e.g., vaccinia). Contingency plans may also be required calling for quarantine of $\mathrm{OV}$-treated patients if treatment toxicity is associated with a longer period of shedding. In reality, to date there has been no instance in which transmission of an OV from a patient to a caregiver or other contact has been demonstrated, and there are no examples of long-term virus persistence or shedding in a treated patient.

In light of the inconvenience and undesirability of OV shedding, there is interest in engineering strategies that may selectively interfere with the process. As one example, wild-type measles virus is a highly transmissible airborne virus that uses the nectin- 4 receptor to enter into airway epithelial cells from whence its progeny are shed into respiratory secretions [192,193]. Eliminating the nectin- 4 tropism by strategically mutating key surface residues in the hemagglutinin attachment protein results in a virus that still causes measles in nonhuman primates, but which is no longer shed into respiratory secretions or urine [194]. Measles virus RNA (but not infectious virus) was detected in the blood, urine and saliva of myeloma patients up to 3 weeks after IV administration of an oncolytic measles virus, especially at higher dose levels, and it is possible that this shedding might be eliminated by using a nectin- 4 blind version of the virus [195] . Virus shedding has also been detected in human clinical trials of HSV, reovirus, vaccinia, reovirus and adenovirus oncolytics, but was less readily detected following IT therapy with oncolytic VSV and polioviruses [167]. However, 
it should be noted that while genome sequences have been detected in shed material, infectious virus particles have not been recovered.

In an OV-treated patient pre-existing antiviral immunity can be a formidable barrier to efficacy, particularly if the virus is administered intravenously. However, pre-existing antiviral immunity in caregivers and patient contacts provides reassuring protection against virus transmission. Conversely, when this particular efficacy barrier is circumvented by using OVs engineered for antibody evasion or selected for low seroprevalence, the risk of epidemic spread in the human population, unchecked by pre-existing herd immunity, looms larger.

An alternative strategy often used to side step antibody neutralization, at least of the first dose of virus administered, is to use OVs derived from zoonotic animal viruses such as New Castle disease virus (chicken), VSV (cattle), myxomavirus (rabbit), Seneca Valley virus (pig) or mengovirus (e.g., mouse and monkey). Additional regulatory

\section{EXECUTIVE SUMMARY}

\section{Viruses as anticancer drugs}

- Viruses naturally possess many properties that favor infection of cancer cells. Enhancing these natural properties and adding new properties through directed evolution and genetic engineering are used to create oncolytic viruses (OVs), which are emerging as a new anticancer drug class.

- OVs target tumor tissues, kill tumor cells directly, amplify antitumor immunity and must be safe for the patient and healthcare workers.

- The diversity of virus families and engineering techniques allows for the creation of OVs with a wide range of properties that can be tailored for each type of cancer.

\section{Delivery of OVs}

- OVs do not obey conventional pharmacological principles due to their ability to be biologically amplified after administration.

- Intravenous delivery allows a virus to reach distant sites of metastasis via the circulation, but extravasation into the tumor parenchyma is inefficient.

- Intratumoral injection can concentrate virus at a site of tumor growth, but regression of distant tumors requires that the virus spread systemically or induce a systemic antitumor immune response.

- Neutralizing antibodies, hepatosplenic sequestration of the virus by macrophages and dilution of the virus in blood or tissue may limit the effectiveness of treatment.

\section{Viral spread}

- Targeting viral spread to tumor cells can be accomplished by transductional targeting (modifying receptor tropism), transcriptional targeting (controlling virus gene expression with tumor-specific promoters), physiologic targeting (disrupting viral immune combat proteins), apoptosis targeting (disrupting viral antiapoptotic proteins) or miRNA targeting.

- Viral replication in the tumor and subsequent spread from infected to uninfected cells is critical for tumor eradication.

\section{Arming viruses with transgenes}

- The addition of transgenes allows tumor cells that escape viral infection to be killed by bystander effects or be better targeted by the immune system.

- Secreted toxins, prodrug convertases and immunostimulatory proteins have been incorporated into OVs to increase treatment efficacy.

\section{Safety}

- Careful steps must be taken to avoid the creation of OVs that might evolve to become serious pathogens.

- Contingency plans to terminate the spread and/or transmission of an infection can increase clinical confidence in viral therapy.

- Ideally, OVs should be nontransmissible. 
scrutiny is generally required for these viruses (e.g., from the US Department of Agriculture) to address the additional risks of environmental release and epidemic spread in domestic animals, particularly as they relate to agricultural livestock.

\section{Conclusion \& future perspective}

Viruses are at last being harnessed for the benefit of cancer patients. The OV field has moved well beyond proof of principle in human studies, and virus engineering will be the key to its continued advancement in the coming years. Virtually every component of every naturally occurring or laboratory-adapted virus can be engineered and/or evolved to enhance its suitability for cancer therapy and we are currently witnessing unstoppable creative activity in this area. Safety is obviously of paramount importance in this relatively new field, and is therefore closely regulated from the design stage to clinical implementation. Considering the current trajectory of OV research, there can be little doubt that viruses are on their way to becoming one of the foundational modalities of future cancer treatment regimens.

\section{Financial \& competing interests disclosure}

Stephen Russell is a cofounder, stakeholder, Board Member and officer (CEO) of Vyriad, an oncolytic virotherapy company. Dr. Kah-Whye Peng is a cofounder, stakeholder and officer (CTO) of Vyriad. Stephen Russell is NIH funded (CA186781-02A1P1). The authors have no other relevant affiliations or financial involvement with any organization or entity with a financial interest in or financial conflict with the subject matter or materials discussed in the manuscript apart from those disclosed.

No writing assistance was utilized in the production of this manuscript.

\section{Open access}

This work is licensed under the AttributionNon Commercial-NoDerivatives 4.0 Unported License. To view a copy of this license, visit http://creativecommons.org/ licenses/by-nc-nd/4.0/

\section{References}

1 Breitbach CJ, Lichty BD, Bell JC. Oncolytic viruses: therapeutics with an identity crisis. EBioMedicine 9, 31-36 (2016).

2 Russell SJ, Peng KW, Bell JC. Oncolytic virotherapy. Nat. Biotechnol. 30 (7), 658-670 (2012).

3 Miest TS, Cattaneo R. New viruses for cancer therapy: meeting clinical needs. Nat. Rev. Microbiol. 12(1), 23-34 (2014).

4 Kelly E, Russell SJ. History of oncolytic viruses: genesis to genetic engineering. Mol. Ther. 15(4), 651-659 (2007).

5 Cattaneo R, Miest T, Shashkova EV, Barry MA. Reprogrammed viruses as cancer therapeutics: targeted, armed and shielded. Nat. Rev. Microbiol. 6(7), 529-540 (2008).

6 Liu TC, Galanis E, Kirn D. Clinical trial results with oncolytic virotherapy: a century of promise, a decade of progress. Nat. Clin. Pract. Oncol. 4(2), 101-117 (2007).

7 Bell J, Mcfadden G. Viruses for tumor therapy. Cell Host Microbe 15(3), 260-265 (2014).

8 Naik S, Nace R, Federspiel MJ, Barber GN, Peng KW, Russell SJ. Curative one-shot systemic virotherapy in murine myeloma. Leukemia 26(8), 1870-1878 (2012).

9 Yu YA, Galanis C, Woo Y et al. Regression of human pancreatic tumor xenografts in mice after a single systemic injection of recombinant vaccinia virus GLV-1h68. Mol. Cancer Ther. 8(1), 141-151 (2009).

10 Eager RM, Nemunaitis J. Clinical development directions in oncolytic viral therapy. Cancer Gene Ther. 18(5), 305-317 (2011).

11 Russell SJ, Federspiel MJ, Peng KW et al. Remission of disseminated cancer after systemic oncolytic virotherapy. Mayo Clin. Proc. 89(7), 926-933 (2014).

12 Andtbacka RH, Ross M, Puzanov I et al. Patterns of clinical response with talimogene laherparepvec (T-VEC) in patients with melanoma treated in the OPTiM Phase III clinical trial. Ann. Surg. Oncol. 23(13), 4169-4177 (2016).

13 Puzanov I, Milhem MM, Minor D et al. Talimogene laherparepvec in combination with ipilimumab in previously untreated, unresectable stage IIIB-IV melanoma. J. Clin. Oncol. 34(22), 2619-2626 (2016).

14 Verheije MH, Lamfers ML, Wurdinger T et al. Coronavirus genetically redirected to the epidermal growth factor receptor exhibits effective antitumor activity against a malignant glioblastoma. J. Virol. 83(15), 7507-7516 (2009).

15 Wurdinger T, Verheije MH, Raaben $\mathrm{M}$ et al. Targeting non-human coronaviruses to human cancer cells using a bispecific single-chain antibody. Gene Ther. 12(18), 1394-1404 (2005).
16 Van Rikxoort M, Michaelis M, Wolschek M et al. Oncolytic effects of a novel influenza A virus expressing interleukin-15 from the NS reading frame. PLoS ONE 7(5), e36506 (2012).

17 Kasloff SB, Pizzuto MS, Silic-Benussi M, Pavone S, Ciminale V, Capua I. Oncolytic activity of avian influenza virus in human pancreatic ductal adenocarcinoma cell lines. J. Virol. 88(16), 9321-9334 (2014).

18 Mansour M, Palese P, Zamarin D. Oncolytic specificity of Newcastle disease virus is mediated by selectivity for apoptosis-resistant cells. J. Virol. 85(12), 6015-6023 (2011).

19 Msaouel P, Opyrchal M, Domingo Musibay E, Galanis E. Oncolytic measles virus strains as novel anticancer agents. Expert Opin. Biol. Ther. 13(4), 483-502 (2013).

20 Galanis E, Atherton PJ, Maurer MJ et al. Oncolytic measles virus expressing the sodium iodide symporter to treat drugresistant ovarian cancer. Cancer Res. 75(1), 22-30 (2015).

21 Csatary LK, Moss RW, Beuth J, Torocsik B, Szeberenyi J, Bakacs T. Beneficial treatment of patients with advanced cancer using a Newcastle disease virus vaccine (MTH-68/H). Anticancer Res. 19(1B), 635-638 (1999).

22 Asada T. Treatment of human cancer with mumps virus. Cancer 34(6), 1907-1928 (1974). 
23 Ammayappan A, Russell SJ, Federspiel MJ. Recombinant mumps virus as a cancer therapeutic agent. Mol. Ther. Oncolytics 3, 16019 (2016).

24 Hutzen B, Raffel C, Studebaker AW. Advances in the design and development of oncolytic measles viruses. Oncolytic Virother. 4, 109-118 (2015).

25 Ruiz AJ, Russell SJ. MicroRNAs and oncolytic viruses. Curr. Opin. Virol. 13, 40-48 (2015).

26 Brown MC, Dobrikov MI, Gromeier M. Mitogen-activated protein kinase-interacting kinase regulates mTOR/AKT signaling and controls the serine/arginine-rich protein kinase-responsive type 1 internal ribosome entry site-mediated translation and viral oncolysis. J. Virol. 88(22), 13149-13160 (2014).

27 Reddy PS, Burroughs KD, Hales LM et al. Seneca Valley virus, a systemically deliverable oncolytic picornavirus, and the treatment of neuroendocrine cancers. J. Natl Cancer Inst. 99(21), 1623-1633 (2007).

28 Gong J, Sachdev E, Mita AC, Mita MM. Clinical development of reovirus for cancer therapy: an oncolytic virus with immunemediated antitumor activity. World J. Methodol. 6(1), 25-42 (2016).

29 Twitty CG, Diago OR, Hogan DJ et al. Retroviral replicating vectors deliver cytosine deaminase leading to targeted 5-fluorouracilmediated cytotoxicity in multiple human cancer types. Hum. Gene Ther. Methods 27(1), 17-31 (2016)

30 Cloughesy TF, Landolfi J, Hogan DJ et al. Phase I trial of vocimagene amiretrorepvec and 5-fluorocytosine for recurrent high-grade glioma. Sci. Transl. Med. 8(341), 341ra375 (2016).

$31 \operatorname{Logg}$ CR, Logg A, Matusik RJ, Bochner $\mathrm{BH}$, Kasahara N. Tissue-specific transcriptional targeting of a replicationcompetent retroviral vector. J. Virol. 76(24), 12783-12791 (2002).

32 Tai CK, Logg CR, Park JM, Anderson WF, Press MF, Kasahara N. Antibody-mediated targeting of replication-competent retroviral vectors. Hum. Gene Ther. 14(8), 789-802 (2003).

33 Zhang L, Steele MB, Jenks N et al. Safety studies in tumor and non-tumor-bearing mice in support of clinical trials using oncolytic VSV-IFNbeta-NIS. Hum. Gene Ther. Clin. Dev. 27(3), 111-122 (2016)

34 Pol JG, Zhang L, Bridle BW et al. Maraba virus as a potent oncolytic vaccine vector. Mol. Ther. 22(2), 420-429 (2014).
35 Muharemagic D, Labib M, Ghobadloo SM, Zamay AS, Bell JC, Berezovski MV. Anti-Fab aptamers for shielding virus from neutralizing antibodies. J. Am. Chem. Soc. 134(41), 17168-17177 (2012).

36 Bourgeois-Daigneault MC, Roy DG, Falls T et al. Oncolytic vesicular stomatitis virus expressing interferon-gamma has enhanced therapeutic activity. Mol. Ther. Oncolytics 3, 16001 (2016)

37 Tesfay MZ, Kirk AC, Hadac EM et al. PEGylation of vesicular stomatitis virus extends virus persistence in blood circulation of passively immunized mice. J. Virol. 87(7), 3752-3759 (2013).

38 Hastie E, Grdzelishvili VZ. Vesicular stomatitis virus as a flexible platform for oncolytic virotherapy against cancer. J. Gen. Virol. 93(Pt 12), 2529-2545 (2012).

39 Unno Y, Shino Y, Kondo F et al. Oncolytic viral therapy for cervical and ovarian cancer cells by Sindbis virus AR339 strain. Clin. Cancer Res. 11(12), 4553-4560 (2005).

40 Ramachandran M, Yu D, Dyczynski M et al. Safe and effective treatment of experimental neuroblastoma and glioblastoma using systemically administered triple microRNA-detargeted oncolytic Semliki Forest virus. Clin. Cancer Res. doi:10.1158/1078-0432.CCR-16-0925 (2016) (Epub ahead of print).

41 Quetglas JI, Labiano S, Aznar MA et al. Virotherapy with a semliki forest virus-based vector encoding IL12 synergizes with PD-1/ PD-L1 blockade. Cancer Immunol. Res. 3(5), 449-454 (2015).

42 Granot T, Yamanashi Y, Meruelo D. Sindbis viral vectors transiently deliver tumorassociated antigens to lymph nodes and elicit diversified antitumor $\mathrm{CD} 8{ }^{+} \mathrm{T}$-cell immunity. Mol. Ther. 22(1), 112-122 (2014).

43 Alemany R, Balague C, Curiel DT. Replicative adenoviruses for cancer therapy. Nat. Biotechnol. 18(7), 723-727 (2000).

44 Trujillo MA, Oneal MJ, Mcdonough SJ, Morris JC. Viral dose, radioiodide uptake, and delayed efflux in adenovirus-mediated NIS radiovirotherapy correlates with treatment efficacy. Gene Ther. 20(5), 567-574 (2013).

45 Grunwald GK, Vetter A, Klutz K et al. EGFR-targeted adenovirus dendrimer coating for improved systemic delivery of the theranostic NIS gene. Mol. Ther. Nucleic Acids 2, e131 (2013).

46 Post DE, Sandberg EM, Kyle MM et al. Targeted cancer gene therapy using a hypoxia inducible factor dependent oncolytic adenovirus armed with interleukin-4. Cancer Res. 67(14), 6872-6881 (2007)

47 Choi IK, Lee JS, Zhang SN et al. Oncolytic adenovirus co-expressing IL-12 and IL-18 improves tumor-specific immunity via differentiation of $\mathrm{T}$ cells expressing IL-12Rbeta2 or IL-18Ralpha. Gene Ther. 18(9), 898-909 (2011).

48 Rehman H, Silk AW, Kane MP, Kaufman HL. Into the clinic: talimogene laherparepvec (T-VEC), a first-in-class intratumoral oncolytic viral therapy. J. Immunother. Cancer 4, 53 (2016)

49 Cuddington BP, Mossman KL. Oncolytic bovine herpesvirus type 1 as a broad spectrum cancer therapeutic. Curr. Opin. Virol. 13, 11-16 (2015)

50 Wong RJ, Chan MK, Yu Z et al. Effective intravenous therapy of murine pulmonary metastases with an oncolytic herpes virus expressing interleukin 12. Clin. Cancer Res. 10 (1 Pt 1), 251-259 (2004).

51 Friedman GK, Beierle EA, Gillespie GY et al. Pediatric cancer gone viral. Part II: potential clinical application of oncolytic herpes simplex virus-1 in children. Mol. Ther. Oncolytics 2, pii: 15016 (2015).

52 Campadelli-Fiume G, Petrovic B, Leoni V et al. Retargeting strategies for oncolytic herpes simplex viruses. Viruses 8(3), 63 (2016).

53 Mazzacurati L, Marzulli M, Reinhart B et al. Use of miRNA response sequences to block off-target replication and increase the safety of an unattenuated, glioblastoma-targeted oncolytic HSV. Mol. Ther. 23(1), 99-107 (2015).

54 Menotti L, Nicoletti G, Gatta V et al. Inhibition of human tumor growth in mice by an oncolytic herpes simplex virus designed to target solely HER-2-positive cells. Proc. Natl Acad. Sci. USA 106(22), 9039-9044 (2009).

55 Marchini A, Bonifati S, Scott EM, Angelova AL, Rommelaere J. Oncolytic parvoviruses: from basic virology to clinical applications. Virol. J. 12, 6 (2015).

56 Haag A, Menten P, Van Damme J, Dinsart C, Rommelaere J, Cornelis JJ. Highly efficient transduction and expression of cytokine genes in human tumor cells by means of autonomous parvovirus vectors; generation of antitumor responses in recipient mice. Hum. Gene Ther. 11(4), 597-609 (2000).

57 Chan WM, Mcfadden G. Oncolytic poxviruses. Annu. Rev. Virol. 1(1), 119-141 (2014).

58 Flint SJ, Racaniello VR, Rall GF, Skalka AM, Enquist LW. Principles of Virology 
(4th Edition). ASM Press, Washington, DC, USA (2015).

59 Wagner EK, Wagner EK. Basic Virology (3rd Edition). Blackwell Publishing, MA, USA (2008).

60 Bailey K, Kirk A, Naik S et al. Mathematical model for radial expansion and conflation of intratumoral infectious centers predicts curative oncolytic virotherapy parameters. PLoS ONE 8(9), e73759 (2013).

61 Miller A, Suksanpaisan L, Naik S et al. Reporter gene imaging identifies intratumoral infection voids as a critical barrier to systemic oncolytic virus efficacy. Mol. Ther. Oncolytics 1,14005 (2014).

62 Breitbach CJ, Burke J, Jonker D et al. Intravenous delivery of a multi-mechanistic cancer-targeted oncolytic poxvirus in humans. Nature 477(7362), 99-102 (2011).

63 Manickan E, Smith JS, Tian J et al. Rapid Kupffer cell death after intravenous injection of adenovirus vectors. Mol. Ther. 13(1), 108-117 (2006).

64 Russell SJ, Peng KW. Viruses as anticancer drugs. Trends Pharmacol. Sci. 28(7), 326-333 (2007).

65 Miller AC, Russell SJ. Heterogeneous delivery is a barrier to the translational advancement of oncolytic virotherapy for treating solid tumors. Virus Adapt. Treat. 6, 11-31 (2014).

66 Miller A, Nace R, Ayala-Breton CC et al. Perfusion pressure is a critical determinant of the intratumoral extravasation of oncolytic viruses. Mol. Ther. 24(2), 306-317 (2016).

67 Fang J, Nakamura H, Maeda H. The EPR effect: unique features of tumor blood vessels for drug delivery, factors involved, and limitations and augmentation of the effect. Adv. Drug Deliv. Rev. 63(3), 136-151 (2011).

68 Hallak LK, Merchan JR, Storgard CM, Loftus JC, Russell SJ. Targeted measles virus vector displaying echistatin infects endothelial cells via alpha(v)beta3 and leads to tumor regression. Cancer Res. 65(12), 5292-5300 (2005).

69 Jing $\mathrm{Y}$, Tong $\mathrm{C}$, Zhang J et al. Tumor and vascular targeting of a novel oncolytic measles virus retargeted against the urokinase receptor. Cancer Res. 69(4), 1459-1468 (2009).

70 Breitbach CJ, De Silva NS, Falls TJ et al. Targeting tumor vasculature with an oncolytic virus. Mol. Ther. 19(5), 886-894 (2011).

71 Myers R, Coviello C, Erbs P et al. Polymeric cups for cavitation-mediated delivery of oncolytic vaccinia virus. Mol. Ther. 4(9), 1627-1633 (2016).
72 Nande R, Howard CM, Claudio PP. Ultrasound-mediated oncolytic virus delivery and uptake for increased therapeutic efficacy: state of art. Oncolytic Virother. 4, 193-205 (2015).

73 Kaufman HL, Amatruda T, Reid T et al. Systemic versus local responses in melanoma patients treated with talimogene laherparepvec from a multi-institutional Phase II study. J. Immunother. Cancer 4, 12 (2016).

74 Ott PA, Hodi FS. Talimogene laherparepvec for the treatment of advanced melanoma. Clin. Cancer Res. 22(13), 3127-3131 (2016).

75 Sauthoff $\mathrm{H}, \mathrm{Hu}$ J, Maca C et al. Intratumoral spread of wild-type adenovirus is limited after local injection of human xenograft tumors: virus persists and spreads systemically at late time points. Hum. Gene Ther. 14(5), 425-433 (2003).

76 Liu CS, Russell SJ, Peng KW. Systemic therapy of disseminated myeloma in passively immunized mice using measles virus-infected cell carriers. Mol. Ther. 18(6), 1155-1164 (2010).

77 Tesfay MZ, Ammayappan A, Federspiel MJ et al. Vesiculovirus neutralization by natural IgM and complement. J. Virol. 88(11), 6148-6157 (2014).

78 Guo ZS, Parimi V, O'malley ME et al. The combination of immunosuppression and carrier cells significantly enhances the efficacy of oncolytic poxvirus in the pre-immunized host. Gene Ther. 17(12), 1465-1475 (2010).

79 Lang SI, Giese NA, Rommelaere J, Dinsart C, Cornelis JJ. Humoral immune responses against minute virus of mice vectors. J. Gene Med. 8(9), 1141-1150 (2006).

80 Sun JY, Anand-Jawa V, Chatterjee S, Wong KK. Immune responses to adeno-associated virus and its recombinant vectors. Gene Ther. 10(11), 964-976 (2003).

81 Peng KW, Myers R, Greenslade A et al. Using clinically approved cyclophosphamide regimens to control the humoral immune response to oncolytic viruses. Gene Ther. 20(3), 255-261 (2013).

82 Bangari DS, Mittal SK. Current strategies and future directions for eluding adenoviral vector immunity. Curr. Gene Ther. 6(2), 215-226 (2006).

83 Miest TS, Yaiw KC, Frenzke M et al. Envelope-chimeric entry-targeted measles virus escapes neutralization and achieves oncolysis. Mol. Ther. 19(10), 1813-1820 (2011).

84 Lech PJ, Tobin GJ, Bushnell R et al. Epitope dampening monotypic measles virus hemagglutinin glycoprotein results in resistance to cocktail of monoclonal antibodies. PLoS ONE 8(1), e52306 (2013).

85 Lech PJ, Pappoe R, Nakamura T, Tobin GJ, Nara PL, Russell SJ. Antibody neutralization of retargeted measles viruses. Virology 454-455 , 237-246 (2014).

86 Shashkova EV, Doronin K, Senac JS, Barry MA. Macrophage depletion combined with anticoagulant therapy increases therapeutic window of systemic treatment with oncolytic adenovirus. Cancer Res. 68(14), 5896-5904 (2008).

87 Koski A, Rajecki M, Guse K et al. Systemic adenoviral gene delivery to orthotopic murine breast tumors with ablation of coagulation factors, thrombocytes and Kupffer cells. J. Gene Med. 11(11), 966-977 (2009).

88 Liu YP, Tong C, Dispenzieri A, Federspiel MJ, Russell SJ, Peng KW. Polyinosinic acid decreases sequestration and improves systemic therapy of measles virus. Cancer Gene Ther. 19(3), 202-211 (2012).

89 Laurenzana A, Margheri F, Chilla A et al. Endothelial progenitor cells as shuttle of anticancer agents. Hum. Gene Ther. doi:10.1089/hum.2016.066 (2016) (Epub ahead of print).

90 Russell SJ, Peng KW. The utility of cells as vehicles for oncolytic virus therapies. Curr. Opin. Mol. Ther. 10(4), 380-386 (2008).

91 Mader EK, Maeyama Y, Lin Y et al. Mesenchymal stem cell carriers protect oncolytic measles viruses from antibody neutralization in an orthotopic ovarian cancer therapy model. Clin. Cancer Res. 15(23), 7246-7255 (2009).

92 Thorne $\mathrm{SH}$, Contag $\mathrm{CH}$. Combining immune cell and viral therapy for the treatment of cancer. Cell. Mol. Life Sci. 64(12), 1449-1451 (2007).

93 Bluming AZ, Ziegler JL. Regression of Burkitt's lymphoma in association with measles infection. Lancet 2(7715), 105-106 (1971).

94 Klimstra WB, Ryman KD, Johnston RE. Adaptation of Sindbis virus to BHK cells selects for use of heparan sulfate as an attachment receptor. J. Virol. 72(9), 7357-7366 (1998).

95 Ong HT, Timm MM, Greipp PR et al. Oncolytic measles virus targets high CD46 expression on multiple myeloma cells. Exp. Hematol. 34(6), 713-720 (2006).

96 Schneider U, Bullough F, Vongpunsawad S, Russell SJ, Cattaneo R. Recombinant measles viruses efficiently entering cells through targeted receptors. J. Virol. 74(21), 9928-9936 (2000). 
97 Nakamura T, Peng KW, Harvey M et al. Rescue and propagation of fully retargeted oncolytic measles viruses. Nat. Biotechnol. 23(2), 209-214 (2005).

98 Verheije MH, Rottier PJ. Retargeting of viruses to generate oncolytic agents. $A d v$. Virol. 2012, 798526 (2012).

99 Van Den Wollenberg DJ, Van Den Hengel SK, Dautzenberg IJ, Cramer SJ, Kranenburg O, Hoeben RC. A strategy for genetic modification of the spike-encoding segment of human reovirus T3D for reovirus targeting. Gene Ther. 15(24), 1567-1578 (2008).

100 Ammayappan A, Peng KW, Russell SJ. Characteristics of oncolytic vesicular stomatitis virus displaying tumor-targeting ligands. J. Virol. 87(24), 13543-13555 (2013).

101 Okazaki K. Proteolytic cleavage of glycoprotein B is dispensable for in vitro replication, but required for syncytium formation of pseudorabies virus. J. Gen. Virol. 88(Pt 7), 1859-1865 (2007).

102 Springfeld C, Von Messling V, Frenzke M, Ungerechts G, Buchholz CJ, Cattaneo R. Oncolytic efficacy and enhanced safety of measles virus activated by tumor-secreted matrix metalloproteinases. Cancer Res. 66(15), 7694-7700 (2006).

103 Morodomi Y, Yano T, Kinoh $\mathrm{H}$ et al. BioKnife, a uPA activity-dependent oncolytic Sendai virus, eliminates pleural spread of malignant mesothelioma via simultaneous stimulation of uPA expression. Mol. Ther. 20(4), 769-777 (2012).

104 Alain T, Kim TS, Lun X et al. Proteolytic disassembly is a critical determinant for reovirus oncolysis. Mol. Ther. 15(8), 1512-1521 (2007).

105 Garcia MA, Meurs EF, Esteban M. The dsRNA protein kinase PKR: virus and cell control. Biochimie 89(6-7), 799-811 (2007).

106 Seth RB, Sun L, Chen ZJ. Antiviral innate immunity pathways. Cell Res. 16(2), 141-147 (2006).

107 Barber GN. Host defense, viruses and apoptosis. Cell Death Differ. 8(2), 113-126 (2001).

108 Thomson BJ. Viruses and apoptosis. Int. J. Exp. Pathol. 82(2), 65-76 (2001).

109 Ahmed M, Mckenzie MO, Puckett S, Hojnacki M, Poliquin L, Lyles DS. Ability of the matrix protein of vesicular stomatitis virus to suppress beta interferon gene expression is genetically correlated with the inhibition of host RNA and protein synthesis. J. Virol. 77(8), 4646-4657 (2003).
110 Chou J, Kern ER, Whitley RJ, Roizman B. Mapping of herpes simplex virus-1 neurovirulence to gamma 134.5, a gene nonessential for growth in culture. Science 250(4985), 1262-1266 (1990).

111 He B, Gross M, Roizman B. The gamma(1)34.5 protein of herpes simplex virus 1 complexes with protein phosphatase 1alpha to dephosphorylate the alpha subunit of the eukaryotic translation initiation factor 2 and preclude the shutoff of protein synthesis by double-stranded RNA-activated protein kinase. Proc. Natl Acad. Sci. USA 94(3), 843-848 (1997).

112 Bischoff JR, Kirn DH, Williams A et al. An adenovirus mutant that replicates selectively in p53-deficient human tumor cells. Science 274(5286), 373-376 (1996).

113 Buller RM, Smith GL, Cremer K, Notkins AL, Moss B. Decreased virulence of recombinant vaccinia virus expression vectors is associated with a thymidine kinase-negative phenotype. Nature 317(6040), 813-815 (1985).

114 Tenser RB. Role of herpes simplex virus thymidine kinase expression in viral pathogenesis and latency. Intervirology 32(2), 76-92 (1991).

115 Martuza RL. Conditionally replicating herpes vectors for cancer therapy. J. Clin. Invest. 105(7), 841-846 (2000).

$116 \mathrm{Kim} \mathrm{JH}$, Oh JY, Park BH et al. Systemic armed oncolytic and immunologic therapy for cancer with JX-594, a targeted poxvirus expressing GM-CSF. Mol. Ther. 14(3), 361-370 (2006).

117 Dalba C, Klatzmann D, Logg CR, Kasahara N. Beyond oncolytic virotherapy: replicationcompetent retrovirus vectors for selective and stable transduction of tumors. Curr. Gene Ther. 5(6), 655-667 (2005).

118 Roe T, Reynolds TC, Yu G, Brown PO. Integration of murine leukemia virus DNA depends on mitosis. EMBO J. 12(5), 2099-2108 (1993).

119 Kelly EJ, Hadac EM, Cullen BR, Russell SJ. MicroRNA antagonism of the picornaviral life cycle: alternative mechanisms of interference. PLoS Pathog. 6(3), e1000820 (2010).

120 Wein LM, Wu JT, Kirn DH. Validation and analysis of a mathematical model of a replication-competent oncolytic virus for cancer treatment: implications for virus design and delivery. Cancer Res. 63(6), 1317-1324 (2003).

121 Sattentau Q. Avoiding the void: cell-to-cell spread of human viruses. Nat. Rev. Microbiol. 6(11), 815-826 (2008).
122 Bateman AR, Harrington KJ, Kottke T et al. Viral fusogenic membrane glycoproteins kill solid tumor cells by nonapoptotic mechanisms that promote cross presentation of tumor antigens by dendritic cells. Cancer Res. 62(22), 6566-6578 (2002).

123 Fu X, Tao L, Jin A, Vile R, Brenner MK, Zhang X. Expression of a fusogenic membrane glycoprotein by an oncolytic herpes simplex virus potentiates the viral antitumor effect. Mol. Ther. 7(6), 748-754 (2003).

124 Ayala-Breton C, Russell LO, Russell SJ, Peng KW. Faster replication and higher expression levels of viral glycoproteins give the vesicular stomatitis virus/measles virus hybrid VSV-FH a growth advantage over measles virus. J. Virol. 88(15), 8332-8339 (2014).

125 De Wever O, Mareel M. Role of tissue stroma in cancer cell invasion. J. Pathol. 200 (4), 429-447 (2003).

126 Choi IK, Strauss R, Richter M, Yun CO, Lieber A. Strategies to increase drug penetration in solid tumors. Front. Oncol. 3 , 193 (2013).

127 Yun CO. Overcoming the extracellular matrix barrier to improve intratumoral spread and therapeutic potential of oncolytic virotherapy. Curr. Opin. Mol. Ther. 10(4), 356-361 (2008).

128 Kim JH, Lee YS, Kim H, Huang JH, Yoon AR, Yun CO. Relaxin expression from tumor-targeting adenoviruses and its intratumoral spread, apoptosis induction, and efficacy. J. Natl Cancer Inst. 98(20), 1482-1493 (2006).

129 Ganesh S, Gonzalez-Edick M, Gibbons D, Van Roey M, Jooss K. Intratumoral coadministration of hyaluronidase enzyme and oncolytic adenoviruses enhances virus potency in metastatic tumor models. Clin. Cancer Res. 14(12), 3933-3941 (2008).

130 Guedan S, Rojas JJ, Gros A, Mercade E, Cascallo M, Alemany R. Hyaluronidase expression by an oncolytic adenovirus enhances its intratumoral spread and suppresses tumor growth. Mol. Ther. 18(7), 1275-1283 (2010).

131 Todd S, Towner JS, Semler BL. Translation and replication properties of the human rhinovirus genome in vivo and in vitro. Virology 229(1), 90-97 (1997).

132 Lim KI, Lang T, Lam V, Yin J. Model-based design of growth-attenuated viruses. PLoS Comput. Biol. 2(9), e116 (2006).

133 Hiley CT, Yuan M, Lemoine NR, Wang Y. Lister strain vaccinia virus, a potential therapeutic vector targeting hypoxic tumours. Gene Ther. 17(2), 281-287 (2010). 
134 Laborda E, Puig-Saus C, Cascallo M, Chillon $\mathrm{M}$, Alemany R. Adeno-associated virus enhances wild-type and oncolytic adenovirus spread. Hum. Gene Ther. Methods 24(6), 372-380 (2013).

135 Yuan Y, Allen LJ. Stochastic models for virus and immune system dynamics. Math. Biosci. 234(2), 84-94 (2011).

136 Fitzgerald DJ, Kreitman R, Wilson W, Squires D, Pastan I. Recombinant immunotoxins for treating cancer. Int. J. Med. Microbiol. 293(7-8), 577-582 (2004).

137 Fitzgerald DJ, Wayne AS, Kreitman RJ, Pastan I. Treatment of hematologic malignancies with immunotoxins and antibody-drug conjugates. Cancer Res. 71(20), 6300-6309 (2011)

138 Ladd B, O’Konek JJ, Ostruszka LJ, Shewach DS. Unrepairable DNA double-strand breaks initiate cytotoxicity with HSV-TK/ ganciclovir. Cancer Gene Ther. 18(10), 751-759 (2011).

139 Mesnil M, Piccoli C, Tiraby G, Willecke K, Yamasaki H. Bystander killing of cancer cells by herpes simplex virus thymidine kinase gene is mediated by connexins. Proc. Natl Acad. Sci. USA 93(5), 1831-1835 (1996).

140 Huber BE, Austin EA, Richards CA, Davis ST, Good SS. Metabolism of 5-fluorocytosine to 5-fluorouracil in human colorectal tumor-cells transduced with the cytosine deaminase gene - significant antitumor effects when only a small percentage of tumor-cells express cytosine deaminase. Proc. Natl Acad. Sci. USA 91(17), 8302-8306 (1994).

141 Kaufmann JK, Chiocca EA. Glioma virus therapies between bench and bedside. Neuro-Oncol. 16(3), 334-351 (2014).

142 Yurttas C, Berchtold S, Malek NP, Bitzer M, Lauer UM. Pulsed versus continuous application of the prodrug 5-fluorocytosine to enhance the oncolytic effectiveness of a measles vaccine virus armed with a suicide gene. Hum. Gene Ther. Clin. Dev. 25(2), 85-96 (2014).

143 Hirschowitz EA, Ohwada A, Pascal WR, Russi TJ, Crystal RG. In-vivo adenovirusmediated gene-transfer of the Escherichia coli cytosine deaminase gene to human colon carcinoma-derived tumors induces chemosensitivity to 5 -fluorocytosine. Hum. Gene Ther. 6(8), 1055-1063 (1995).

144 Kasai K, Nakashima H, Liu F et al. Toxicology and biodistribution studies for MGH2.1, an oncolytic virus that expresses two prodrug-activating genes, in combination with prodrugs. Mol. Ther. Nucleic Acids 2, e113 (2013).
145 Ungerechts G, Springfeld C, Frenzke ME et al. An immunocompetent murine model for oncolysis with an armed and targeted measles virus. Mol. Ther. 15(11), 1991-1997 (2007).

146 Dadachova E, Carrasco N. The $\mathrm{Na}^{+} / \mathrm{I}$ symporter (NIS): imaging and therapeutic applications. Semin. Nucl. Med. 34(1), 23-31 (2004).

147 Miller A, Russell SJ. The use of the NIS reporter gene for optimizing oncolytic virotherapy. Expert Opin. Biol. Ther. 16(1), 15-32 (2016).

148 Dingli D, Peng KW, Harvey ME et al. Image-guided radiovirotherapy for multiple myeloma using a recombinant measles virus expressing the thyroidal sodium iodide symporter. Blood 103(5), 1641-1646 (2004).

149 Barton KN, Stricker H, Brown SL et al. Phase I study of noninvasive imaging of adenovirusmediated gene expression in the human prostate. Mol. Ther. 16(10), 1761-1769 (2008).

150 Podbilewicz B. Virus and cell fusion mechanisms. Annu. Rev. Cell. Dev. Biol. 30, 111-139 (2014).

151 Chang A, Dutch RE. Paramyxovirus fusion and entry: multiple paths to a common end. Viruses 4(4), 613-636 (2012).

152 Higuchi $\mathrm{H}$, Bronk SF, Bateman A, Harrington K, Vile RG, Gores GJ. Viral fusogenic membrane glycoprotein expression causes syncytia formation with bioenergetic cell death: implications for gene therapy. Cancer Res. 60 (22), 6396-6402 (2000).

153 Shin EJ, Chang JI, Choi B et al. Fusogenic vesicular stomatitis virus for the treatment of head and neck squamous carcinomas. Otolaryngol. Head Neck Surg. 136(5), 811-817 (2007).

154 Diaz RM, Bateman A, Emiliusen L et al. A lentiviral vector expressing a fusogenic glycoprotein for cancer gene therapy. Gene Ther. 7(19), 1656-1663 (2000).

155 Guedan S, Grases D, Rojas JJ et al. GALV expression enhances the therapeutic efficacy of an oncolytic adenovirus by inducing cell fusion and enhancing virus distribution. Gene Ther. 19(11), 1048-1057 (2012).

156 Simpson GR, Coffin RS. Construction and characterization of an oncolytic HSV vector containing a fusogenic glycoprotein and prodrug activation for enhanced local tumor control. Methods Mol. Biol. 542, 551-564 (2009).

157 Hanahan D, Weinberg RA. Hallmarks of cancer: the next generation. Cell 144(5), 646-674 (2011).

158 Rabinovich GA, Gabrilovich D, Sotomayor EM. Immunosuppressive strategies that are mediated by tumor cells. Annu. Rev. Immunol. 25, 267-296 (2007).

159 Pardoll DM. The blockade of immune checkpoints in cancer immunotherapy. Nat. Rev. Cancer 12(4), 252-264 (2012).

160 Engeland CE, Grossardt C, Veinalde R et al. CTLA-4 and PD-L1 checkpoint blockade enhances oncolytic measles virus therapy. Mol. Ther. 22(11), 1949-1959 (2014).

161 Ivashkiv LB, Donlin LT. Regulation of type I interferon responses. Nat. Rev. Immunol. 14(1), 36-49 (2014).

162 Moehler MH, Zeidler M, Wilsberg V et al. Parvovirus H-1-induced tumor cell death enhances human immune response in vitro via increased phagocytosis, maturation, and cross-presentation by dendritic cells. Hum. Gene Ther. 16(8), 996-1005 (2005).

163 Guo ZS, Liu Z, Bartlett DL. Oncolytic immunotherapy: dying the right way is a key to eliciting potent antitumor immunity. Front. Oncol. 4, 74 (2014).

164 Shen WW, Patnaik MM, Ruiz A, Russell SJ, Peng KW. Immunovirotherapy with vesicular stomatitis virus and PD-L1 blockade enhances therapeutic outcome in murine acute myeloid leukemia. Blood 127(11), 1449-1458 (2016).

165 Lichty BD, Breitbach CJ, Stojdl DF, Bell JC. Going viral with cancer immunotherapy. Nat. Rev. Cancer 14(8), 559-567 (2014).

166 Patel MR, Kratzke RA. Oncolytic virus therapy for cancer: the first wave of translational clinical trials. Transl. Res. 161(4), 355-364 (2013).

167 Buijs PR, Verhagen JH, Van Eijck CH, Van Den Hoogen BG. Oncolytic viruses: from bench to bedside with a focus on safety. Hum. Vaccin. Immunother. 11(7), 1573-1584 (2015).

168 Pol J, Buque A, Aranda F et al. Trial Watch - oncolytic viruses and cancer therapy. Oncoimmunology 5(2), e1117740 (2016).

169 Lawler SE, Speranza MC, Cho CF, Chiocca EA. Oncolytic viruses in cancer treatment: a review. JAMA Oncol. doi:10.1001/ jamaoncol.2016.2064 (2016) (Epub ahead of print).

170 Southam CM, Moore AE. Clinical studies of viruses as antineoplastic agents with particular reference to Egypt 101 virus. Cancer 5(5), 1025-1034 (1952).

171 Hoster HA, Zanes RP Jr, Von Haam E. Studies in Hodgkin's syndrome; the association of viral hepatitis and Hodgkin's disease; a preliminary report. Cancer Res. 9(8), 473-480 (1949). 
172 Lancaster KZ, Pfeiffer JK. Viral population dynamics and virulence thresholds. Curr. Opin. Microbiol. 15(4), 525-530 (2012).

173 Korboukh VK, Lee CA, Acevedo A et al. RNA virus population diversity, an optimum for maximal fitness and virulence. J. Biol. Chem. 289(43), 29531-29544 (2014).

174 Andino R, Domingo E. Viral quasispecies. Virology 479-480, 46-51 (2015).

175 Holland J, Spindler K, Horodyski F, Grabau E, Nichol S, Vandepol S. Rapid evolution of RNA genomes. Science 215(4540), 1577-1585 (1982).

176 Pfeiffer JK, Kirkegaard K. Increased fidelity reduces poliovirus fitness and virulence under selective pressure in mice. PLoS Pathog. 1(2), e11 (2005).

177 Griffin DE, Pan CH. Measles: old vaccines, new vaccines. Curr. Top. Microbiol. Immunol. 330, 191-212 (2009).

178 Agut H, Kean KM, Bellocq C, Fichot O, Girard M. Intratypic recombination of polioviruses: evidence for multiple crossingover sites on the viral genome. J. Virol. 61(5), 1722-1725 (1987).

179 Yang CF, Chen HY, Jorba J et al. Intratypic recombination among lineages of type 1 vaccine-derived poliovirus emerging during chronic infection of an immunodeficient patient. J. Virol. 79(20), 12623-12634 (2005).

180 Hampson AW, Mackenzie JS. The influenza viruses. Med. J. Aust. 185 (Suppl. 10), S39-S43 (2006).
181 Bergmann M, Romirer I, Sachet M et al. A genetically engineered influenza $A$ virus with ras-dependent oncolytic properties. Cancer Res. 61(22), 8188-8193 (2001).

182 Peters C, Rabkin SD. Designing herpes viruses as oncolytics. Mol. Ther. Oncolytics 2, pii:15010 (2015).

183 Razonable RR. Antiviral drugs for viruses other than human immunodeficiency virus. Mayo Clin. Proc. 86(10), 1009-1026 (2011).

184 Ji X, Zhang J, Cheng L et al. Oncolytic adenovirus delivering herpes simplex virus thymidine kinase suicide gene reduces the growth of human retinoblastoma in an in vivo mouse model. Exp. Eye Res. 89(2), 193-199 (2009).

185 Zhou X, Brenner MK. Improving the safety of T-cell therapies using an inducible caspase-9 gene. Exp. Hematol. 44(11), 1013-1019 (2016).

186 Zhou X, Naik S, Dakhova O, Dotti G, Heslop HE, Brenner MK. Serial activation of the inducible caspase 9 safety switch after human stem cell transplantation. Mol. Ther. 24(4), 823-831 (2016).

187 Abate-Daga D, Andreu N, Camacho-Sanchez $\mathrm{J}$ et al. Oncolytic adenoviruses armed with thymidine kinase can be traced by PET imaging and show potent antitumoural effects by ganciclovir dosing. PLoS ONE 6(10), e26142 (2011).

188 Willmon CL, Saloura V, Fridlender ZG et al. Expression of IFN-beta enhances both efficacy and safety of oncolytic vesicular stomatitis virus for therapy of mesothelioma. Cancer Res. 69(19), 7713-7720 (2009).
189 Stojdl DF, Lichty BD, Tenoever BR et al. VSV strains with defects in their ability to shutdown innate immunity are potent systemic anti-cancer agents. Cancer Cell 4(4), 263-275 (2003).

190 Vile R, Ando D, Kirn D. The oncolytic virotherapy treatment platform for cancer: unique biological and biosafety points to consider. Cancer Gene Ther. 9(12), 1062-1067 (2002).

191 Aghi M, Martuza RL. Oncolytic viral therapies - the clinical experience. Oncogene 24(52), 7802-7816 (2005).

192 Frenzke M, Sawatsky B, Wong XX et al. Nectin-4-dependent measles virus spread to the cynomolgus monkey tracheal epithelium: role of infected immune cells infiltrating the lamina propria. J. Virol. 87(5), 2526-2534 (2013).

193 Ludlow M, Lemon K, De Vries RD et al. Measles virus infection of epithelial cells in the macaque upper respiratory tract is mediated by subepithelial immune cells. J. Virol. 87(7), 4033-4042 (2013).

194 Leonard VH, Sinn PL, Hodge G et al. Measles virus blind to its epithelial cell receptor remains virulent in rhesus monkeys but cannot cross the airway epithelium and is not shed. J. Clin. Invest. 118(7), 2448-2458 (2008).

195 Baldo A, Galanis E, Tangy F, Herman P. Biosafety considerations for attenuated measles virus vectors used in virotherapy and vaccination. Hum. Vaccin. Immunother. 12(5), 1102-1116 (2016). 